\title{
SEGMENTAÇÃO MULTIRRESOLUÇÃO E CLASSIFICAÇÃO ORIENTADA A OBJETOS APLICADOS A IMAGENS SPOT-5 PARA O MAPEAMENTO DO USO DA TERRA
}

\author{
Naíssa Batista da Luz ${ }^{1}$, Alzir Felippe Buffara Antunes ${ }^{2}$, João Batista Tavares Júnior ${ }^{3}$ \\ ${ }^{1}$ Eng ${ }^{a}$ Florestal, M.Sc., Doutoranda em Ciências Geodésicas, UFPR, Curitiba, PR, Brasil - naissa@ ufpr.br \\ ${ }^{2}$ Eng. Cartográfico, Dr., Depto. de Geomática, UFPR, Curitiba, PR, Brasil - felipe@ufpr.br \\ ${ }^{3}$ Eng. Agrimensor, M.Sc., Doutorando em Ciências Geodésicas, UFPR, Curitiba, PR, Brasil - joaotavaresjunior@ yahoo.com.br
}

Recebido para publicação: 05/12/2007 - Aceito para publicação: 29/06/2009

\begin{abstract}
Resumo
A abordagem de classificação orientada a objetos representa um novo paradigma no processamento de imagens de alta resolução espacial. A utilização de descritores espectrais e de forma, oriundos da segmentação, permitem uma melhor discriminação seletiva entre os objetos. Funções de pertinência fuzzy podem ser construídas a partir das propriedades dos objetos segmentados. Atualmente, o estado do Paraná vem realizando atualização dos mapas de uso da terra em escala 1:50.000 por meio de ortorretificação de imagens Spot 5. Pretende-se neste trabalho elaborar o mapa de uso da terra por meio de técnicas de segmentação multiresolução e classificação contextualizada (lógica fuzzy). Descritores dos objetos foram selecionados por estatística multivariada, métodos das componentes principais e de discriminantes, determinando-se aqueles com maior potencial de separabilidade entre as classes. Testes de classificação sucessivos foram realizados aplicando-se funções de pertinência fuzzy aos descritores selecionados, procedendo-se à classificação final da imagem. O mapa de uso da terra, abrangendo uma área de aproximadamente $218,75 \mathrm{~km}^{2}$, resultou em um valor de acurácia Kappa em torno de $80 \%$ (utilizando-se os objetos selecionados como amostras de treinamento), demonstrando o potencial dessa ferramenta, embora posteriores adaptações metodológicas devam ser implementadas.

Palavras-chave: Imagem de alta resolução espacial; lógica fuzzy; hierarquia de classes; rede semântica.
\end{abstract}

\begin{abstract}
Multiresolution segmentation, object-oriented classification and Spot-5 imagery land use mapping. The object oriented classification approach represents a new paradigm to the high spatial resolution imagery processing. The use of spectral and form properties originated from the segmentation procedure allows better discrimination between objects. Fuzzy membership functions are generated from the segmented objects descriptors. The State of Parana has been currently updating its 1:50.000 land use maps by means of Spot 5 orthorectified imagery. The objective of this paper is to develop a methodology to the elaboration of land use maps by means of multi-resolution segmentation techniques and image contextual classification with the aid of fuzzy logic. In order to identify which descriptors could provide better class separability, multivariate statistic, principal components and discriminant analysis techniques were used, as a result potential descriptors were selected. Finally the classification process was achieved using those descriptors to create the fuzzy sets and the membership functions. The Land Use Map generated, including an area of $218,75 \mathrm{~km}^{2}$, reached a Kappa index near to $80 \%$, indicating the potential application of this technique nevertheless subsequent methodological adaptation might be implemented. Keywords: High spatial resolution imagery; object oriented classification; fuzzy logic; land use mapping.
\end{abstract}

\section{INTRODUÇÃO}

Os tradicionais classificadores digitais foram desenvolvidos baseados em características do pixel como unidade primitiva de informações a respeito dos alvos, sendo denominados por essa abordagem de classificadores pixel a pixel, sobretudo voltados a imagens de baixa resolução espacial. A melhoria da resolução espacial trazida com o avanço tecnológico evidenciou a dificuldade de aplicação desses classificadores (BLÄSCHKE; STROBL, 2001). Enquanto que em imagens de baixa resolução espacial um 
único pixel pode armazenar a resposta espectral de mais de um objeto, ou uma área heterogênea de um mesmo objeto, em imagens de alta resolução um pixel possui características espectrais semelhantes às de seus vizinhos, sendo mais puro em termos de mistura espectral (MACHADO; CAETANO, 2002).

Dada a dificuldade de extração de informações a partir de imagens de alta resolução espacial, diversos autores têm adotado com sucesso uma nova abordagem de processamento, na qual a unidade primitiva de processamento não é mais o pixel, e sim objetos compostos por vários pixels, por essa razão chamada de classificação orientada a objetos (BAATZ; SHÄPE, 2000; WHITESIDE; AHMAD, 2005; CHUBEY et al., 2006; ZHONG et al., 2005; AVCI et al., 2006; ARGIALAS; TZOTSOS, 2006; MOELLER; BLÄSCHKE, 2006; EHLERS et al., 2006; SHIBA; ITAYA, 2006; CHUNYANG et al., 2005; FRAUMAN; WOLFF, 2005; WILLHAUCK, et al., 2000). Essa nova abordagem pretende aproximar as técnicas de processamento e extração de informações com o raciocínio humano, ou seja, com a forma de pensar e de reconhecer padrões que intuitivamente adotamos ao interpretar uma imagem ou apreciar uma paisagem (BAATZ; SCHÄPE, 2000).

O primeiro passo para que o cérebro humano seja capaz de identificar e separar as informações contidas em uma imagem se dá no reconhecimento da forma dos objetos, sendo posteriormente comparados com padrões já pré-definidos em nossas mentes (DEFINIENS IMAGING, 2004). Em busca de um processo capaz de delinear os objetos contidos em uma imagem de alta resolução espacial próximo ao raciocínio humano, criou-se um método de delineamento denominado segmentação multirresolução (ZHONG et al., 2005). A técnica empregada pela segmentação multirresolução realiza o agrupamento de pixels com características espectrais semelhantes, analisando o tamanho, a homogeneidade espectral, a homogeneidade espacial e a forma do objeto (CHUBEY et al., 2006).

De acordo com Antunes (2003), o conjunto de segmentos que formam os objetos ou feições de uma imagem pode ser organizado hierarquicamente. Assim, as segmentações em diferentes níveis de escala podem ser obtidas pelo agrupamento dos objetos do nível ligeiramente abaixo (WILLHAUCK et al., 2000), dando origem à terminologia denominada subobjeto e superobjeto. A palavra subobjeto é empregada para indicar que um determinado objeto se encontra em um nível de segmentação mais detalhado, enquanto que a expressão superobjeto é utilizada para caracterizar o objeto em um nível mais grosseiro, sendo este resultante do agrupamento dos subobjetos. A rede hierárquica permite também que as feições de diferentes escalas possam ser representadas simultaneamente e classificadas umas em relação às outras (KERSTING, 2006).

Após a realização do processo de delineamento dos objetos em uma imagem, a próxima etapa consiste em atribuí-los a determinada classe, através da comparação dos objetos identificados na imagem com padrões anteriormente pré-definidos, realizando assim a classificação dos objetos da imagem considerando-os tematicamente homogêneos, sendo chamada de classificação orientada a objetos (WHITESIDE; AHMAD, 2005).

A classificação orientada a objetos é realizada respeitando-se a hierarquia da segmentação, porém parte do nível mais grosseiro (superobjeto) para o nível mais detalhado (subobjeto). Durante o processo de classificação dos objetos de uma imagem, dois fatores devem ser considerados: os descritores dos objetos que permitem o processo de diferenciação de cada classe e o classificador a ser utilizado (ZHANG, 2006).

Os descritores empregados para efetuar a caracterização das classes equivalem às aplicações de funções matemáticas que possibilitam revelar os atributos dos objetos da imagem. Dentre as possibilidades de classificação, sobressai-se o classificador que adota a regra fuzzy de pertinência para associar os objetos às classes, seguindo um raciocínio próximo à lógica humana (PINHO et al., 2005).

Este trabalho tem como objetivo realizar uma avaliação preliminar dessa nova abordagem de classificação, aplicada a uma imagem do satélite Spot-5 para uma área no estado do Paraná, adotando-se uma legenda pré-definida para o mapeamento do uso do solo do estado. O mapeamento mencionado vem sendo realizado utilizando-se classificadores tradicionais pixel a pixel, como o algoritmo de máxima verossimilhança.

\section{Revisão dos conceitos}

Segmentação multirresolução

A técnica de segmentação multirresolução é considerada similar à utilizada pelo processo de segmentação por crescimento de região (ANTUNES, 2003), na qual cada pixel é rotulado seguindo um critério de similaridade para cada par de regiões adjacentes espacialmente (GONZALES; WOODS, 2000). Ambas as técnicas realizam um teste de hipótese estatístico que testa a média entre as regiões para realizar o 
agrupamento considerando os critérios de similaridade, diferenciando-se pelo fato de que a segmentação multirresolução considera os parâmetros de forma.

Durante o processo, a metodologia adotada pela segmentação multirresolução particiona a imagem em regiões homogêneas, podendo ser influenciada por parâmetros de escala, tonalidade e forma, em que:

- o parâmetro de escala influencia a heterogeneidade dos pixels, definindo o tamanho dos objetos;

- a tonalidade equilibra a homogeneidade das cores dos segmentos com a homogeneidade da figura;

- o parâmetro de forma promove o equilíbrio entre a suavidade da borda de um segmento e a compacidade, estabilizando os critérios de homogeneidade dos objetos primários (WHITESIDE; AHMAD, 2005).

Baatz; Schäpe (1999) ressaltam que a característica principal do procedimento está relacionada ao fato dos novos segmentos possuírem relações com os segmentos que as constituem num nível hierárquico mais baixo, permitindo o reagrupamento dos objetos, formando objetos maiores (superobjeto).

Assim, a segmentação multirresolução é realizada com base em parâmetros espectrais e de forma, que formam os objetos do nível superior (superobjeto) pelo agrupamento dos objetos do nível inferior (subobjeto), permitindo que as feições de diferentes escalas possam ser representadas simultaneamente e serem classificadas umas em relação às outras (KERSTING, 2006).

Utilização da lógica fuzzy na classificação de objetos

A teoria de conjuntos fuzzy foi introduzida com o intuito de dar um tratamento matemático aos termos que apresentam ambiguidade, abstração e ambivalência, fundamentando-se em sua capacidade de inferir conclusões e gerar respostas a partir dessas informações (RUHOFF et al., 2005). A lógica fuzzy é interessante no processo de classificação digital, porque foi desenvolvida a partir de uma generalização da teoria dos conjuntos tradicionais, os quais não possibilitam efetuar o tratamento de problemas que gerem paradoxos. O sistema fuzzy permite a tomada de decisões fora dos extremos de "completamente falso" ou "completamente verdadeiro", aplicando uma premissa para o grau de verdade, adotando valores que variam de 0 a 1 , o que permite que se levem em conta os resultados tidos como "parcialmente verdadeiros" ou "parcialmente falsos" (MOLENAAR; CHENG, 2000).

Seguindo o raciocínio adotado pela teoria dos conjuntos clássicos, temos de forma análoga para a lógica fuzzy o seguinte desenvolvimento:

Seja $F$ um conjunto e $T$ um subconjunto de $F$. O conjunto $T$ é expresso pela função característica dada por:

$$
C_{T}(x)=\left\{\begin{array}{lll}
1 & \text { se } & x \in T \\
0 & \text { se } & x \notin T
\end{array}\right.
$$

Assim, $C_{T}$ é uma função cujo domínio é $F$ e a imagem está contida no conjunto $\{0,1\}$, com $C_{T}(x)=1$ indicando a existência do elemento $\mathrm{x}$ no conjunto $T$, enquanto $C_{T}(x)=0$ indica a sua inexistência no conjunto $T$.

Para quebrar a característica de sim ou não e poder trabalhar com a hipótese de se e então, criou-se uma espécie de relaxamento no conjunto imagem, formalizando um subconjunto denominado fuzzy.

Agora, seja $F$ um conjunto (clássico). Um subconjunto fuzzy $A$ de $F$ é caracterizado por uma função $\mu_{A}: F \rightarrow[0,1]$, chamada função de pertinência do conjunto fuzzy $F$.

O valor $\mu_{A}(x) \in[0,1]$ indica o grau com que o elemento $x$ de $A$ está no conjunto fuzzy $F$, onde $\mu_{A}(x)=0 \mathrm{e} \mu_{A}(x)=1$ indica a não-pertinência e a pertinência completa de $x$ ao conjunto fuzzy $A$ (BARROS, 2005).

A seguir, apresenta-se um exemplo de lógica fuzzy utilizando a caracterização de áreas de floresta e agricultura em imagens pancromáticas. Na lógica clássica, só é possível dizer se a área é coberta por floresta ou agricultura classificando um pixel que tenha nível de cinza igual a 124 no mesmo grupo de um pixel com nível de cinza igual a 100, podendo-se representar essa função conforme demonstrado na Figura 1.

De acordo com a Figura 2, para a lógica fuzzy o limite de negação total é do nível de pixel igual a 100 e de aprovação total é de 150. Isso quer dizer que se o nível de cinza de determinada área for igual a 100 , com certeza ela não é coberta por florestas, enquanto que se for igual a 150, com certeza é floresta. Valores abaixo de 100 garantiriam que a área não é floresta, enquanto que valores acima de 150 garantiriam 
que a área é florestal. As áreas com valores de nível de cinza entre 100 e 150 são classificadas de acordo com o seu grau de pertinência. Assim, o conjunto fuzzy expressa um grau que indica o quanto determinado elemento pertence a um conjunto, baseando-se em uma função de pertinência que assume valores contínuos e variáveis entre 0 e 1 (ANTUNES, 2003). Dessa forma, o processo de tomada de decisão realizado pela lógica boolena é similar ao processo adotado pelo raciocínio humano, o qual, de acordo com certo grau de ambigüidade, classifica determinado objeto pertencente a uma dada classe.

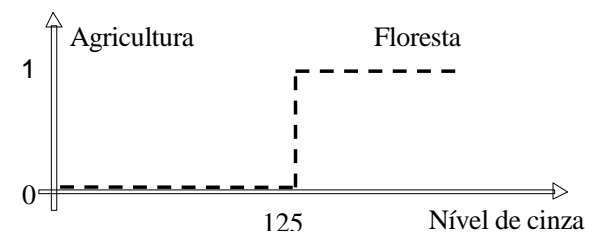

Figura 1. Lógica clássica, onde 0 é empregado para classificar as áreas agrícolas e 1 para classificar áreas florestais.

Figure 1. The classical logic, where 0 is employed to classify agricultural areas and 1 to classify forest areas.

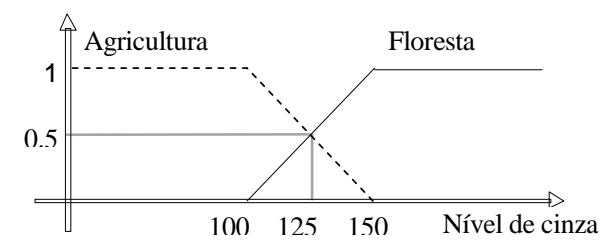

Figura 2. A linha pontilhada indica a função de pertinência de áreas agrícolas, e a linha cheia, áreas florestais. A linha cinza indica o limite de pertinência para uma função booleana.

Figure 2. The dashed line indicates agricultural areas membership function and the full line, forest areas membership function. The gray line indicates the limit for the boolean membership function.

\section{MATERIAL E MÉTODOS}

\section{Área de estudo}

Para a realização deste trabalho, foram utilizadas imagens do satélite Spot-5, sensor HRS (High Resolution Stereoscopic), obtidas em 26 de maio de 2005 de uma região no interior do estado do Paraná e adquiridas com nível de processamento $1 \mathrm{~A}$ (ortorretificada com modelo numérico do terreno com curvas equidistantes de $20 \mathrm{~m}$ ). As imagens têm resolução espacial de $5 \mathrm{~m}$, e foram utilizadas as bandas do vermelho e do verde, da região do visível, e a banda do infravermelho próximo.

A imagem original, com 12000x12000 pixels, foi recortada, originando uma imagem de $3500 \mathrm{x}$ 2500 pixels (Figura 8), cujas coordenadas dos cantos superior esquerdo e inferior direito correspondem a

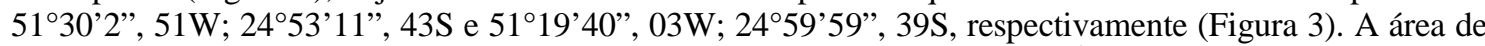
abrangência da imagem corresponde, portanto, a aproximadamente $218,75 \mathrm{~km}^{2}$. Adicionalmente às imagens, arquivos digitais contendo informações vetoriais dos rios existentes na área também foram incluídos no processamento, visando à melhor classificação dos leitos e áreas adjacentes a eles. Os arquivos vetoriais são provenientes da base cartográfica digital do Projeto Paraná Cidade.

\section{Segmentação da imagem}

O algoritmo de segmentação de imagens FNEA (Fractal Net Evolution Approach), implementado no software e-cognition 4.1, é parte da abordagem segmentação multirresolução, assim denominada pela possibilidade de extração de objetos da imagem em diferentes escalas, isto é, com determinado nível de detalhamento, de acordo com os objetivos do usuário e as características das feições de interesse. 


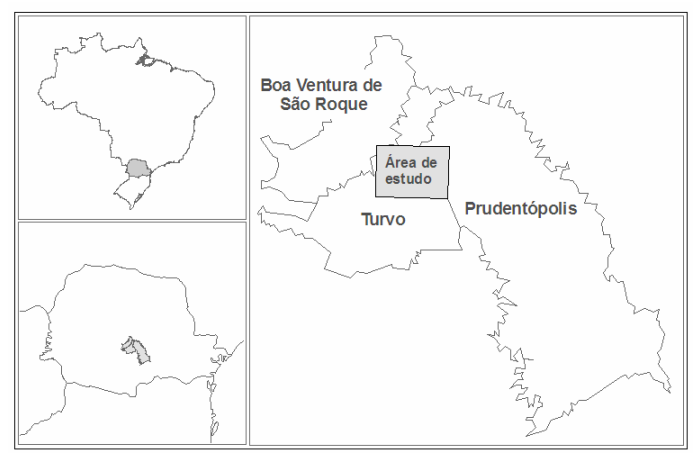

Figura 3. Localização da área de estudo.

Figure 3. Study area location.

A segmentação multiresolução se dá através de um processo heurístico de decisão, que se baseia em um critério de fusão, determinado pela heterogeneidade das características espectrais e espaciais dos objetos da imagem. Além da heterogeneidade (quando a semelhança entre os objetos é analisada), leva-se em consideração também um fator de escala, que determina o tamanho médio dos objetos, dependendo das necessidades do usuário (BAATZ; SCHÄPE, 1999; BLASCHKE; STROBL, 2001).

$\mathrm{O}$ processo de segmentação multirresolução inicia-se com um pixel, considerado um objeto ou região inicial, que é comparado com os objetos vizinhos, calculando-se a heterogeneidade dos objetos antes e depois de sua fusão (DEFINIENS IMAGING, 2004). A diferença entre as heterogeneidades (Equação 1) calculadas para os dois momentos é que define o custo de fusão dos objetos, de forma comparativa, buscando-se a menor heterogeneidade.

$$
h_{d i f}=h_{m}-\frac{\left(h_{1} * n_{1}+h_{2}\right)}{n_{2}+n_{1}}
$$

Em que: $h_{1}$ e $h_{2}$ representam a heterogeneidade para dois objetos;

$h_{m}$ representa a heterogeneidade após a fusão virtual;

$n$ é o tamanho dos objetos.

A heterogeneidade é definida por duas componentes: a heterogeneidade espectral e a heterogeneidade espacial, que leva em consideração a forma dos objetos gerados. A heterogeneidade espectral é definida pela Equação 2.

$$
h_{\text {espectral }}=\sum_{c} w_{c} * \sigma_{c}
$$

Em que: $\sigma_{c}=$ desvio padrão dos valores espectrais em cada banda;

$w_{c}=$ peso atribuído a cada banda.

A heterogeneidade de forma ( ${ }^{h_{\text {forma }}}$ ) (Equação 3) é definida de acordo com dois outros critérios, denominados suavidade e compacidade. A heterogeneidade de forma é avaliada de maneira semelhante ao anteriormente exposto para a heterogeneidade espectral. Dado o agrupamento de dois objetos, calcula-se a situação anterior e posterior à fusão deles, calculando-se a diferença na heterogeneidade. Dessa forma, a suavidade e a compacidade são calculadas de acordo com as equações 4 e 5.

$$
h_{\text {forma }}=w_{\text {compac }} * h_{\text {compac }}+\left(1-w_{\text {compac }}\right) * h_{\text {suavid }}
$$

Em que: $w_{\text {compac }}=$ peso atribuído para compacidade.

$$
\begin{aligned}
& h_{\text {suavid }}=n_{\text {agrup }} * \frac{l_{\text {agrup }}}{b_{\text {agrup }}}-\left(n_{o b j 1} * \frac{l_{o b j 1}}{b_{o b j 1}}+n_{o b j 2} * \frac{l_{o b j 2}}{b_{o b j 2}}\right) \\
& h_{\text {compac }}=n_{\text {agrup }} * \frac{l_{\text {agrup }}}{\sqrt{n_{\text {agrup }}}}-\left(n_{o b j 1} * \frac{l_{o b j 1}}{\sqrt{n_{o b j 1}}}+n_{o b j 2} * \frac{l_{o b j 2}}{\sqrt{n_{o b j 2}}}\right)
\end{aligned}
$$


Em que: $n$ é o tamanho dos objetos;

$l$ é o perímetro;

$b$ é o perímetro do retângulo envolvente do objeto.

Durante o processo de segmentação, são criados níveis hierárquicos, através da fusão dos objetos primitivos em superobjetos, formados pelos primeiros, construindo-se uma rede hierárquica, que representa a informação da imagem em diferentes resoluções simultaneamente (DEFINIENS IMAGING, 2004).

Diversos testes de segmentação foram realizados utilizando-se todas as bandas incluídas neste trabalho, avaliando-se visualmente a concordância dos limites dos objetos resultantes com o que se pretende em termos de discriminação entre os objetos. Essa avaliação levou em consideração o tamanho e a forma dos polígonos resultantes. Essas características devem ser compatíveis com os objetivos do mapeamento, a escala de trabalho e as feições a serem identificadas.

Neste contexto, o tamanho dos objetos oriundos da segmentação foi definido de acordo com a escala mínima dos produtos cartográficos possíveis de serem confeccionados com o uso de imagens do sensor Spot-5, como um ponto de partida. Segundo Sabins (1987), a resolução espacial é a característica de uma imagem que define a sua capacidade de distinguir pontos adjacentes, estando relacionada com o tamanho da parcela correspondente no terreno imageado por um elemento do sensor. Assim, os objetos espaçados, porém mais próximos do que o limite de resolução, aparecerão como se fossem um único objeto. Com base nessa relação, Tavares Jr. et al. (2006) sugerem a seguinte equação, aplicada neste trabalho, para calcular a escala mínima dos produtos cartográficos possíveis de serem obtidos de uma imagem (Equação 6). Pela Equação 6, considerando-se o RMS igual a zero para imagens Spot-5, temos um fator de escala igual a 50.000. O produto cartográfico gerado com informações extraídas dessa imagem terá uma escala mínima de 1/50.000, portanto o menor objeto que pode ser identificado nessa imagem deve possuir amplitude mínima de 10 metros. Dessa forma, foram avaliados os polígonos oriundos da segmentação da imagem, de forma que objetos muito pequenos e em desacordo com essas características fossem obtidos.

$$
F e=5.000 *(2 \mathrm{Re}+R M S)
$$

Em que: $\mathrm{Fe}=$ fator de escala;

$\mathrm{Re}=$ resolução espacial;

$R M S$ = erro quadrático médio advindo do processo de georreferenciamento da imagem.

Adicionalmente a essa análise, classificações preliminares foram aplicadas aos objetos, ainda visando à definição dos parâmetros de segmentação. A cada segmentação, o parâmetro de escala foi alterado, gerando-se uma classificação preliminar e avaliando-se visualmente a capacidade de discriminação dos objetos. $\mathrm{O}$ fator de forma, a compacidade e a suavidade foram mantidos constantes. Dada a dificuldade de uma segmentação precisa dos cursos d'água e por não se configurar em um dos objetivos deste trabalho, utilizou-se um arquivo vetorial em formato shapefile, contendo informações temáticas da rede de drenagem da área imageada. Essas informações foram incluídas nos processos de segmentação e de classificação, permitindo a geração de objetos definidos pelas linhas dos polígonos que representam os cursos d'água.

\section{Classificação da imagem}

Com base na possibilidade de segmentação multirresolução e na criação de diversos níveis hierárquicos conectados entre si, em que cada objeto armazena as relações topológicas entre seus vizinhos, seus superobjetos e subobjetos, torna-se viável a utilização de informações semânticas do contexto em que estes estão inseridos, melhorando os resultados da classificação. O algoritmo permite a criação de um grande número de descritores das características dos objetos e de suas relações topológicas, de hierarquia e também de funções fuzzy, para a discriminação entre objetos quando a pertinência dos objetos às classes é calculada.

Rede semântica e hierarquia de classes

A abordagem utilizada neste trabalho permite a inserção de informações cognitivas, como a textura, a forma e a distribuição dos objetos na cena (frequentemente utilizadas por um especialista no reconhecimento e diferenciação entre os objetos), que podem ser inseridas na forma de uma rede hierárquica de conhecimentos ou de uma rede semântica.

Dessa forma, além da hierarquia existente entre os objetos, criada durante o processo de segmentação, é também possível a criação de uma rede semântica hierárquica, que permite de forma 
progressiva que sejam atribuídas classes aos objetos. Estes seriam, portanto, separados inicialmente em grandes grupos, ou classes-mãe, a partir das quais são derivadas as demais classes-filha.

Assim, se tivermos como classes-mãe, por exemplo, áreas urbanas e áreas rurais bem definidas, nunca uma área agrícola ou pastagem será confundida com feições da área urbana.

A construção da hierarquia das classes se deu de forma intuitiva, utilizando-se conhecimentos a respeito do comportamento espectral dos alvos e também das características da vegetação. Os objetivos, nessa etapa do processo, eram promover a categorização dos objetos de forma sucessiva e também explicitar as relações semânticas entre essas classes, de forma a emular o processo de reconhecimento de padrões humano.

\section{Descritores}

Pode ser gerado um grande número de descritores das características dos objetos resultantes da segmentação multirresolução, auxiliando na discriminação entre classes e melhorando os resultados da classificação. Os descritores disponíveis no software e-Cognition 4.1 permitem avaliar:

- $\quad$ as características dos objetos - valores dos layers ou camadas de informação, forma, textura, hierarquia e a utilização de atributos;

- as características relacionadas às classes, como relações entre objetos vizinhos, relações entre superobjetos e subobjetos, associações entre classes;

- as características globais, relacionadas à cena e às classes.

Um conjunto de amostras foi selecionado para cada classe, a partir dos objetos que constituem o $1^{\circ}$ nível de segmentação (de maior detalhe, fator de escala 10, nível dos subobjetos). Optou-se por analisar os objetos do $1^{\circ}$ nível pela percepção de maior facilidade na classificação dos objetos dos demais níveis, além da posterior utilização desse nível para a geração do mapa de uso do solo final. A partir dos objetos oriundos da segmentação que compõe esse nível, foi calculado um conjunto de 360 descritores. Esse conjunto foi incluído na análise estatística multivariada. Foram utilizadas as técnicas de análise de discriminantes e de análise por componentes principais, visando à identificação daqueles com maior potencial de discriminação entre as classes.

A partir do subconjunto de descritores selecionados na etapa anterior, foram gerados gráficos contendo os valores dos descritores para objetos amostrados a partir da imagem segmentada. Esses gráficos permitiram avaliar a distribuição estatística dos descritores e o potencial de separabilidade entre as classes amostradas. Essa análise se deu avaliando-se os pares de classes que apresentaram maior confusão espectral. A partir desses gráficos, também foram elaboradas funções fuzzy e diversos testes de classificação foram realizados, visando o ajuste das funções fuzzy e a seleção dos descritores com efetivo potencial de utilização na classificação. Dessa forma, foram selecionados os descritores utilizados na classificação, cuja formulação é apresentada na tabela 1 (para conhecer a formulação dos demais descritores abordados neste trabalho, consultar Definiens Imaging, 2004).

\section{RESULTADOS E DISCUSSÃO}

\section{Segmentação multirresolução}

Alguns dos resultados da segmentação da imagem, utilizando-se diferentes parâmetros de escala, são ilustrados na figura 4 abaixo, tendo-se selecionado aqueles que representam diferenças visuais significativas no tamanho e forma dos polígonos obtidos. Na figura, apresentam-se as imagens e polígonos gerados com os parâmetros de escala selecionados e também alguns exemplos daqueles descartados. Foram adotados os parâmetros de escala 10, 20 e 30 para a obtenção dos objetos nos níveis de segmentação 1, 2 e 3 , respectivamente, e também o fator de forma de 0,1 , compacidade de 0,5 e suavidade de 0,5 para todas as segmentações.

Como se pode observar na Figura 4, os resultados obtidos na segmentação da imagem com os parâmetros de escala de 80 e 90 no terceiro nível (itens "f" e "i") apresentam limites mais generalizados dos polígonos, sendo que os menores objetos individualizados não permitiriam, em um processo subsequente de classificação, a detecção de nuanças ou heterogeneidade interna aos objetos. Os polígonos resultantes das segmentações com os maiores parâmetros de escala foram considerados inapropriados, pois alguns objetos são demasiadamente grandes, sobretudo se considerada a abordagem de classificação do software utilizado. Como o processo de classificação inicia-se com o resultado da segmentação no nível 3, a utilização de parâmetros de escala maiores do que 30 resultam em objetos que não representam as variações das classes, impedindo que bons resultados sejam obtidos, podendo ocasionar erros de classificação e a geração de classes-mãe que não representam a realidade. Esses erros seriam repassados às classes-filha nos processos subsequentes de classificação. Dessa forma, optou-se pela geração de polígonos menores, que permitirão a obtenção de resultados de classificação mais detalhados. Com base nesses critérios e nos motivos acima expostos, foram selecionados os parâmetros de segmentação adotados. 
Tabela 1. Descritores utilizados.

Table 1. Used descriptors.

\begin{tabular}{|c|c|c|}
\hline Descritores & Modelos matemáticos & Descrições dos descritores \\
\hline Brilho & $\begin{array}{l}\text { Brilho }=\frac{1}{n_{\text {bandas }}} * \sum_{i=1}^{n} \overline{n . c}_{\cdot i} \\
\text { em que: } \\
\overline{n . c} \cdot i \text { é o valor médio da banda i. }\end{array}$ & $\begin{array}{l}\text { Somatória dos valores médios das bandas } \\
\text { espectrais dividida pelo número de } \\
\text { bandas que formam um segmento. }\end{array}$ \\
\hline Média & $\begin{array}{l}\text { Média }=\frac{1}{n} * \sum_{i=1}^{n} n . c . \\
\text { em que: } \\
n: \text { número de pixels que formam o objeto; } \\
n . c .: \text { valor do nível de cinza para determinada } \\
\text { camada e determinado objeto. }\end{array}$ & $\begin{array}{l}\text { A média é umas das características dos } \\
\text { objetos, calculada a partir dos valores das } \\
\text { diferentes camadas de informação (que } \\
\text { podem ser as bandas espectrais), } \\
\text { computando-se o valor médio dos níveis } \\
\text { de cinza dos pixels que formam } \\
\text { determinado objeto. }\end{array}$ \\
\hline $\begin{array}{l}\text { Diferença média } \\
\text { entre objetos } \\
\text { vizinhos }\end{array}$ & $\begin{array}{l}\text { Dif.Média }=\frac{1}{l} * \sum_{i=1}^{n} l_{s i} *\left(\overline{\text { n.c. }}_{\cdot \mathrm{i}}-\overline{n . c}_{\cdot j}\right) \\
\text { em que: } \\
l_{\text {é o comprimento de borda do considerando; }} \\
l_{s i} \text { é o comprimento de borda compartilhado com o } \\
\frac{\text { vizinho direto }}{n}{ }^{n \cdot c}{ }_{\cdot i} \text { é o valor médio dos níveis de cinza do objeto } \\
\text { considerado; } \\
\overline{n . c}_{\cdot j} \text { é o valor médio dos níveis de cinza do objeto } \\
\text { vizinho; } \\
n \text { é a quantidade de vizinhos. }\end{array}$ & $\begin{array}{l}\text { Para cada objeto vizinho, a diferença } \\
\text { média da camada é calculada e ponderada } \\
\text { com relação ao comprimento de borda } \\
\text { entre os objetos. }\end{array}$ \\
\hline $\begin{array}{l}\text { Relações com os } \\
\text { superobjetos }\end{array}$ & & $\begin{array}{l}\text { Esta característica refere-se à existência } \\
\text { de atribuição de classes em objetos em } \\
\text { um nível superior na hierarquia de } \\
\text { objetos. A existência de determinada } \\
\text { classe atribuída ao superobjeto determina } \\
\text { um valor de verdadeiro ou falso. }\end{array}$ \\
\hline Razão & $\begin{array}{l}\text { Razão } o_{\text {banda } i}=\frac{\overline{\mathrm{n}_{\mathrm{c} \cdot \mathrm{c}_{\cdot \mathrm{i}}}}}{\sum_{i=1}^{n} \overline{n \cdot c_{\cdot T}}} \\
\text { em que: } \\
\overline{n \cdot c \cdot i}: \text { valor médio dos níveis da cinza da banda } \mathrm{i} \\
\text { para determinado objeto; } \\
\overline{n \cdot c \cdot T} \text { : valor médio dos níveis de cinza de todas as } \\
\text { bandas. }\end{array}$ & $\begin{array}{l}\text { Razão entre o valor médio dos níveis de } \\
\text { cinza de um objeto e o valor médio dos } \\
\text { níveis de cinza de todas as bandas } \\
\text { espectrais, para um objeto. }\end{array}$ \\
\hline
\end{tabular}

\section{Classificação da imagem}

Rede semântica e hierarquia de classes

O desenvolvimento da hierarquia de classes representando a rede semântica existente entre as elas pode ser considerado uma das etapas mais importantes do processo de classificação orientada a objetos. A separabilidade progressiva dos objetos facilita a discriminação entre as classes, permitindo que sejam aplicadas funções fuzzy a pares de classes e possibilitando a utilização de descritores mais apropriados a tarefas específicas. A hierarquia de classes desenvolvida é composta por três níveis hierárquicos, conforme representado na Figura 5, a partir da qual se pretende representar as relações semânticas entre as classes. 


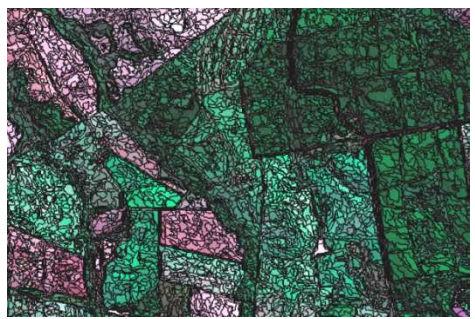

(a) Parâmetro de escala: 10, nível 1

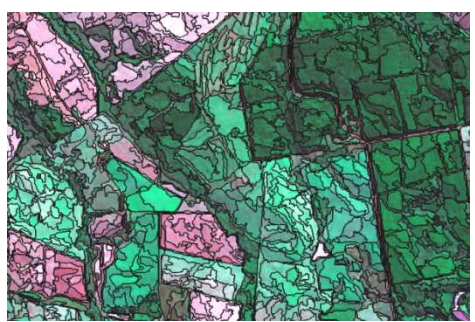

(d) Pa râmetrode escala: 30 , nív el 1

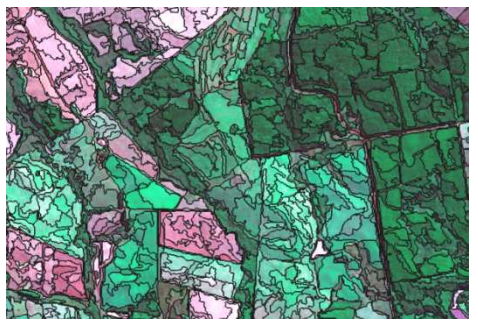

(g) Pa râm etro de escala: 35 , nív el 1

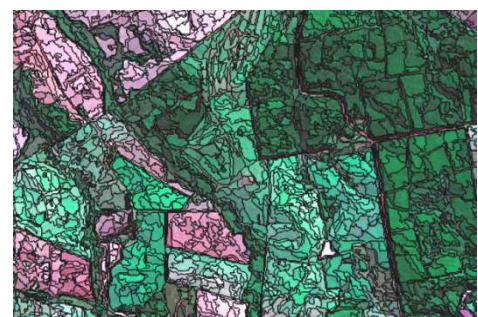

(b) Parâmetro de escala: 20 , nível 2

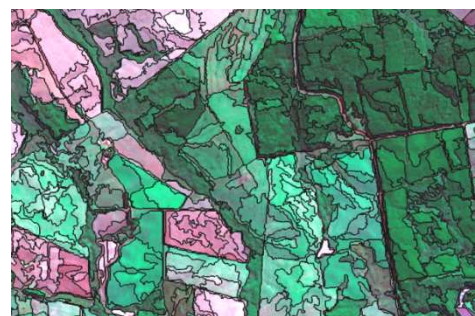

(e) Parâmetro de escala: 50 , nível 2

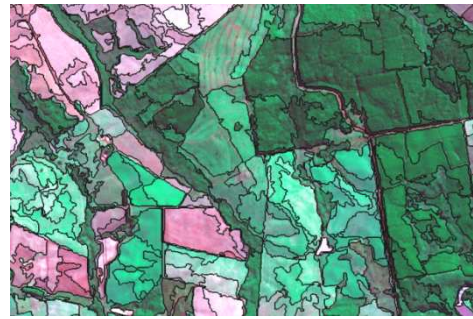

(h) Parâmetro de escala: 70 , nível 2

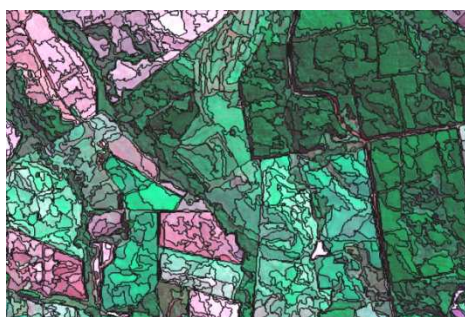

(c) Pa râmetro de escala:30, nível3

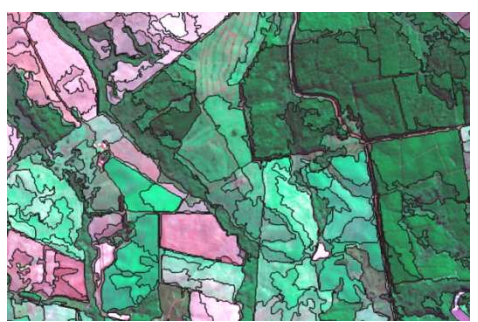

(f) Parâmetro de escala: 80 , nível 3

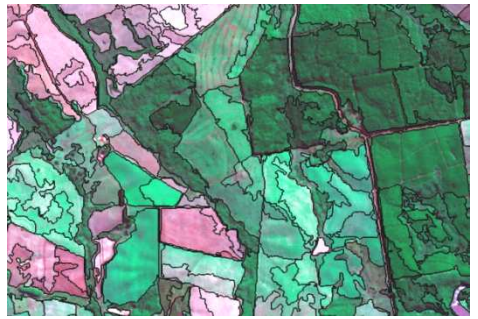

(i) Parâmetro de esca la: 90 , nível 3

Figura 4. Exemplos de resultados obtidos nos testes com a segmentação da imagem.

Figure 4. Examples of results obtained from the image segmentation tests.

Os objetos classificados no nível 1 são resultantes da última segmentação realizada, gerada com fator de escala 30, resultando em objetos maiores, com menor detalhamento. Esses objetos, portanto, podem ser considerados como superobjetos, aos quais são atribuídas as classes denominadas mãe. Essa estrutura de segmentação tem a característica realizar a classificação de baixo para cima (bottom up), ou seja, de um nível de maior para o menor detalhe (subobjetos, objetos e superobjetos), e a classificação de cima para baixo (up bottom), iniciando-se pelos superobjetos.

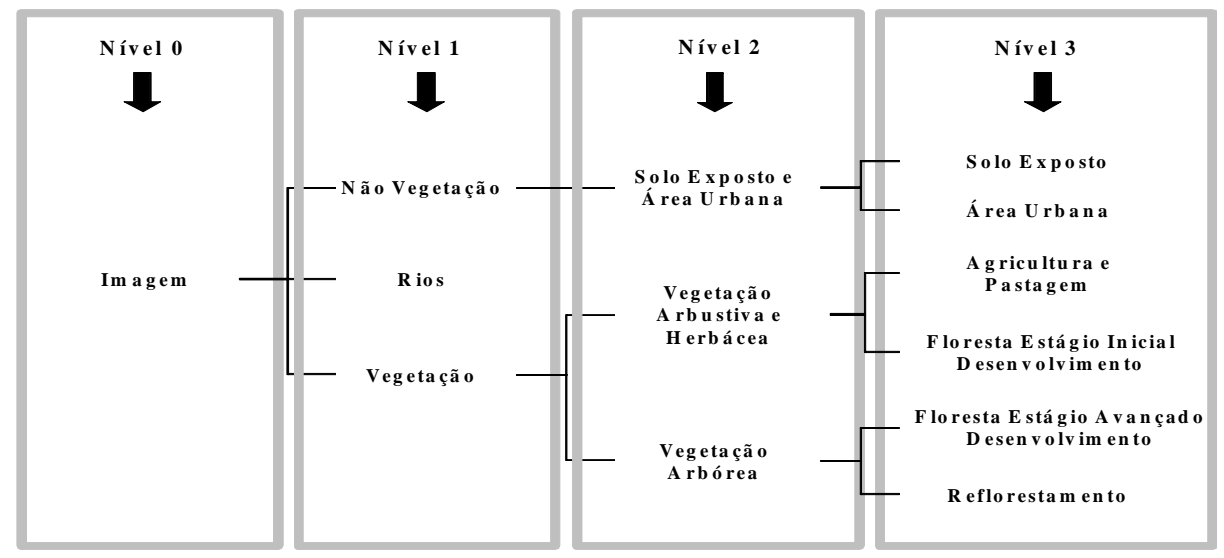

Figura 5. Hierarquia de classes gerada para a classificação da imagem Spot 5 utilizada neste estudo. Figure 5. Class hierarchy generated from the Spot 5 image classification, used in this study. 
A rede semântica desenvolvida é composta por três classes-mãe (vegetação, não-vegetação e rios), formando um primeiro nível. O fator determinante na adoção dessas classes para a classificação dos superobjetos é a existência de grandes diferenças na resposta espectral desses grandes grupos de objetos. $\mathrm{O}$ significado semântico dessa divisão, no entanto, há que ser considerado. A separação da imagem em áreas com e sem vegetação é uma sequência de raciocínio que poderia ser de fato adotada por um analista ou especialista no reconhecimento de padrões, independentemente de sua área de atuação.

Formando o segundo nível, têm-se as classes-filha de vegetação e não-vegetação, já que a classe rios não tem herdeiros nos demais níveis. Assim, as classes-filha de vegetação seriam vegetação arbórea, arbustiva e herbácea, e sob a classe de não-vegetação tem-se a classe-filha composta por áreas urbanas e solo exposto. Finalmente, em um terceiro nível, têm-se as classes de solo exposto, área urbana, agricultura e pastagem, floresta em estágio inicial de desenvolvimento, floresta em estágio avançado de desenvolvimento e reflorestamento.

\section{Descritores}

Análise estatística dos descritores

Considerando-se a abundância de informação passível de ser extraída das imagens originais através da geração de descritores de forma, padrão, textura e vizinhança dos objetos no software, fez-se necessária a avaliação preliminar das características dos descritores (Tabela 2). Nesse sentido, optou-se pela análise estatística dos descritores, visando identificar aqueles que possibilitam maior separabilidade entre as classes, sobretudo aquelas de maior semelhança espectral (como as classes de vegetação, em especial vegetação arbórea). As análises estatísticas multivariadas pelos métodos de componentes principais e de discriminantes auxiliaram na seleção dos melhores descritores para a separabilidade entre as classes.

Na Figura 6 são apresentados os gráficos, gerados a partir da análise de discriminantes, dos descritores que apresentaram melhores resultados na análise estatística multivariada, onde se percebe que alguns descritores têm maior potencial de separabilidade entre as classes.
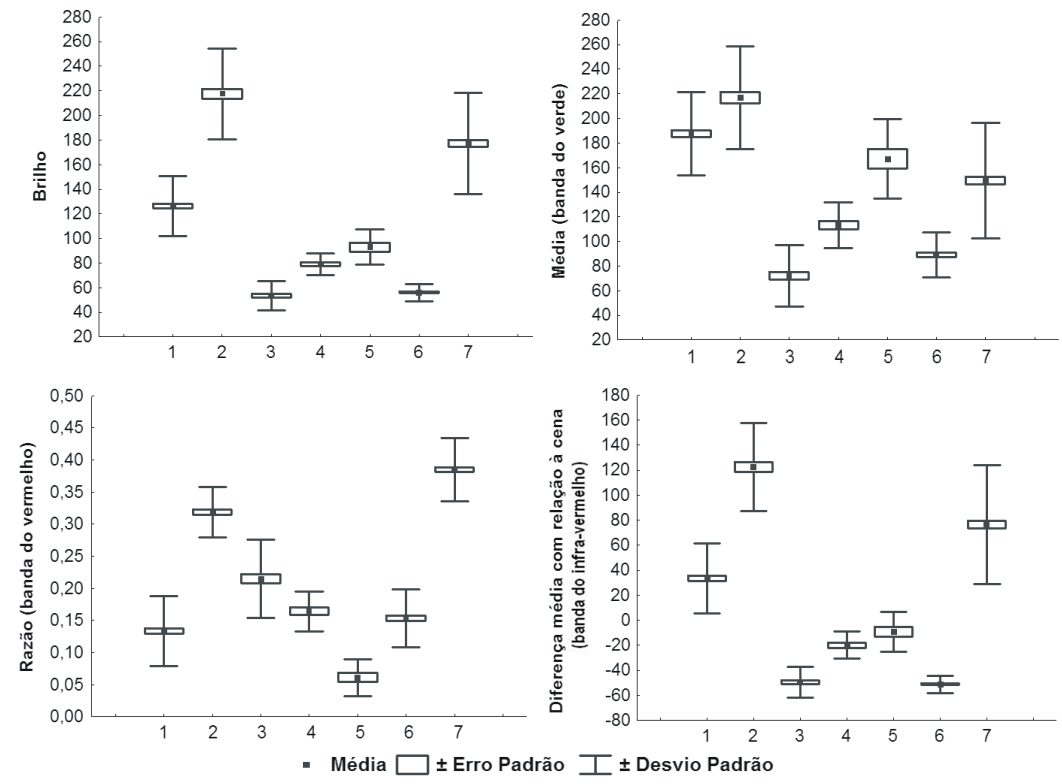

Figura 6. Amostras de objetos, para as 7 classes consideradas (1-agricultura e pastagens, 2-área urbana, 3-floresta estágio avançado de desenvolvimento, 4-floresta estágio inicial de desenvolvimento, 5-floresta estágio médio de desenvolvimento, 6-reflorestamentos, 7-solo exposto), dos descritores média (banda do verde), brilho, razão (banda do vermelho) e diferença média entre vizinhos com relação à cena (banda do infravermelho).

Figure 6. Objects samples for the seven classes were considered (1-agriculture and pastures, 2-urban area, 3 -forest in advanced stage of development, 4-forest in initial stage of development, 5-forest in medium stage of development, 6-planted forests, 7-exposed soil) for the descriptors average (green band), brightness, ratio (red band) and average difference between neighbors related to scene (blue band). 
Tabela 2. Descritores selecionados a partir da análise estatística multivariada (componentes principais e análise de discriminantes) e suas estatísticas descritivas (média, desvio padrão, mínimo e máximo).

Table 2. Descriptors selected from multivariate statistic analysis (principal components and discriminant analysis) and its descriptive statistics (average, standard deviation, minimum and maximum values).

\begin{tabular}{|c|c|c|c|c|}
\hline \multirow[b]{2}{*}{ Descritores* } & \multicolumn{4}{|c|}{ Estatísticas descritivas } \\
\hline & Média & $\begin{array}{l}\text { Desvio } \\
\text { padrão }\end{array}$ & Mínimo & Máximo \\
\hline Área (excluindo-se polígonos internos) $\left(\mathrm{m}^{2}\right)$ & 3521,45 & 3287,18 & 100,00 & 44212,50 \\
\hline Área média representada pelos segmentos $\left(\mathrm{m}^{2}\right)$ & 545,29 & 339,97 & 43,18 & 3049,14 \\
\hline Borda relativa a vizinhos mais claros (3) & 0,42 & 0,31 & 0,00 & 1,00 \\
\hline Brilho & 133,14 & 63,22 & 27,77 & 254,99 \\
\hline Comprimento de borda (m) & 422,72 & 190,47 & 40,00 & 1230,00 \\
\hline Comprimento (m) & 111,27 & 49,21 & 10,00 & 341,77 \\
\hline Coordenada $X$ do centro (m) & 456895,69 & 17567,77 & 4412,77 & 465822,72 \\
\hline Coordenada X mínima (m) & 456851,00 & 17566,63 & 4415,03 & 465780,41 \\
\hline Coordenada Y do centro (m) & 7230496,48 & 271631,06 & 3433,37 & 7247194,66 \\
\hline Coordenada Y mínima (m) & 7230452,10 & 271629,40 & 3433,25 & 7247163,88 \\
\hline Desvio padrão (1) & 5,61 & 5,86 & 0,04 & 44,63 \\
\hline Diferença média absoluta entre vizinhos (1) & 13,05 & 17,78 & 0,33 & 122,43 \\
\hline Diferença média absoluta entre vizinhos (2) & 19,61 & 19,78 & 0,00 & 123,81 \\
\hline Diferença média absoluta entre vizinhos (3) & 16,15 & 19,33 & 0,40 & 133,77 \\
\hline Diferença média com relação à cena (1) & 40,88 & 85,98 & $-62,71$ & 184,60 \\
\hline Diferença média com relação à cena (3) & 34,09 & 67,17 & $-74,06$ & 149,43 \\
\hline Diferença média entre vizinhos (1) & 5,31 & 18,85 & $-33,25$ & 122,43 \\
\hline Diferença média entre vizinhos (3) & 6,86 & 21,45 & $-48,16$ & 133,77 \\
\hline Diferença média entre vizinhos mais claros (3) & 8,70 & 8,92 & 0,00 & 89,38 \\
\hline Diferença média entre vizinhos mais escuros (1) & 12,37 & 19,15 & 0,00 & 122,43 \\
\hline Diferença média entre vizinhos mais escuros (2) & 18,68 & 20,69 & 0,00 & 123,81 \\
\hline Diferença média entre vizinhos mais escuros (3) & 15,48 & 20,84 & 0,00 & 149,01 \\
\hline Distância à borda da imagem (m) & 2672,62 & 1439,91 & 0,00 & 6150,00 \\
\hline Distância à borda direita da imagem (m) & 9339,60 & 4411,27 & 1060,00 & 16805,00 \\
\hline Distância à linha (m) & 3799,69 & 2037,69 & 8,21 & 7700,31 \\
\hline Largura $(\mathrm{m})$ & 60,63 & 26,93 & 5,00 & 221,18 \\
\hline Média (3) & 139,50 & 67,21 & 31,51 & 255,00 \\
\hline Número de segmentos (1) & 9,70 & 4,04 & 2,00 & 28,00 \\
\hline Perímetro do polígono (m) & 355,64 & 157,07 & 40,00 & 1040,34 \\
\hline Razão (1) & 0,25 & 0,12 & 0,03 & 0,56 \\
\hline Razão (2) & 0,40 & 0,12 & 0,12 & 0,64 \\
\hline Razão com relação à cena (1) & 1,58 & 1,22 & 0,11 & 3,62 \\
\hline Razão com relação à cena (2) & 1,19 & 0,47 & 0,16 & 2,03 \\
\hline Razão com relação à cena (3) & 1,32 & 0,64 & 0,30 & 2,42 \\
\hline Valor mínimo dos pixels (1) & 98,55 & 81,30 & 4,00 & 254,00 \\
\hline Valor mínimo dos pixels (3) & 124,87 & 66,46 & 21,00 & 255,00 \\
\hline Valor máximo dos pixels (1) & 123,41 & 87,50 & 11,00 & 255,00 \\
\hline Valor máximo dos pixels (2) & 164,31 & 57,49 & 32,00 & 255,00 \\
\hline Valor máximo dos pixels (3) & 152,79 & 66,69 & 42,00 & 255,00 \\
\hline
\end{tabular}

* Os números entre parênteses representam as bandas às quais foram aplicados os descritores, sendo que os números 1 , 2 e 3 representam as bandas do vermelho, verde e infravermelho, respectivamente.

Na Figura 6, pode-se perceber que a classe de solos expostos (7) é mais facilmente separável das demais, no descritor gerado pelo cálculo da razão (banda do vermelho). A classe de áreas urbanas (2), que apresenta grande confusão com as demais classes, pode ser separada das demais pelos descritores da 
diferença média com relação à cena (calculada para a banda do infravermelho) e também pelo descritor do brilho, bem como parcialmente separável da classe de solos expostos neste segundo descritor. As classes de floresta em seus diferentes estágios de desenvolvimento (3 e 4) são parcialmente separáveis no descritor média (banda do verde), ao passo que as classes de áreas agrícolas e pastagens (1) e de floresta estágio médio de desenvolvimento (5) apresentam separabilidade relativa no descritor da razão (banda do verde).

\section{Funções fuzzy}

A avaliação dos descritores selecionados a partir da análise estatística multivariada permitiu identificar os descritores com maior potencial de separação entre determinadas classes. Como a maior dificuldade de discriminação ocorreu entre pares de classes, esse procedimento se demonstrou bastante útil, dada a dificuldade de discriminar classes com resposta espectral semelhante. Conforme se pode observar na Figura 5, o último nível da rede semântica possui seis classes, sendo que de cada uma das três classes-mãe do nível imediatamente acima provêm duas classes. Assim sendo, pela forma como está estruturada a hierarquia de classes, a maior dificuldade de discriminação entre os objetos se deu entre os pares de classes indicados na Figura 7, optando-se, por esse motivo, por criar as funções de pertinência para separar essas classes entre si.

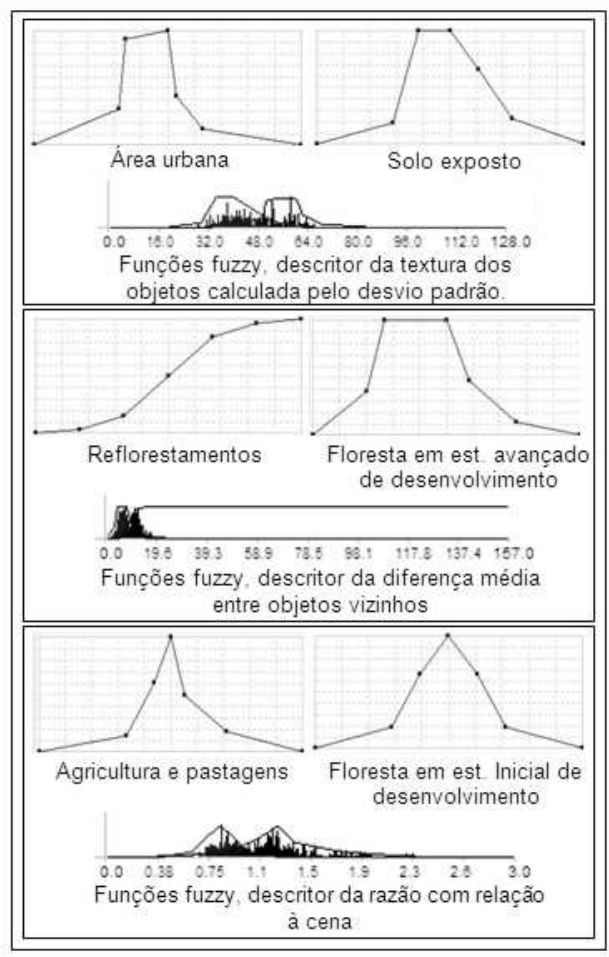

Figura 7. Funções fuzzy geradas a partir dos descritores dos objetos para pares de classes com maior dificuldade de discriminação.

Figure 7. Fuzzy functions generated from the object descriptors for greater discrimination complexity pairs of classes.

\section{Classificação resultante}

A abordagem de classificação do software utilizado neste trabalho permite a utilização dos resultados das segmentações sucessivas nos diversos níveis, com diferentes parâmetros de escala, realizando-se classificações também sucessivas, de forma hierárquica, permitindo-se dessa forma que a herança das classes-mãe (ou seja, os atributos dos objetos e suas classes) sejam repassada às classes-filha. Na Figura 8 são apresentados os resultados das classificações realizadas utilizando-se o resultado das segmentações nos níveis 1,2 e 3 . 
O resultado do $1^{\circ}$ nível de classificação, no qual foram atribuídas classes aos objetos resultantes da segmentação no $3^{\circ}$ nível, foi considerado bastante satisfatório, conforme se pode observar na Figura 8 . Nesse nível, foram separadas as classes de vegetação e não-vegetação. Na tabela 3, apresenta-se a matriz de confusão entre as classes resultante da classificação desse $1^{\circ}$ nível de classificação. A avaliação da acurácia foi realizada com base nos objetos selecionados como amostras de treinamento. Conforme pode ser observado, os resultados obtidos para esse nível foram bastante satisfatórios, já que não houve confusão entre as classes, permanecendo apenas um único objeto não classificado, resultando numa acurácia Kappa total de 0,99 (de um valor máximo de 1). Ainda que tenham sido utilizadas as amostras de treinamento para a avaliação da acurácia da classificação, deve-se ressaltar que o número de amostras coletadas foi bastante grande, dada a facilidade de realização desse procedimento.

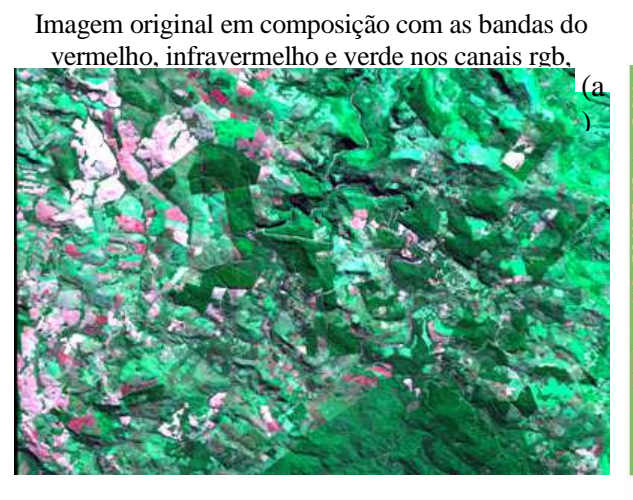

Imagem do nível 3 de segmentação classificada como

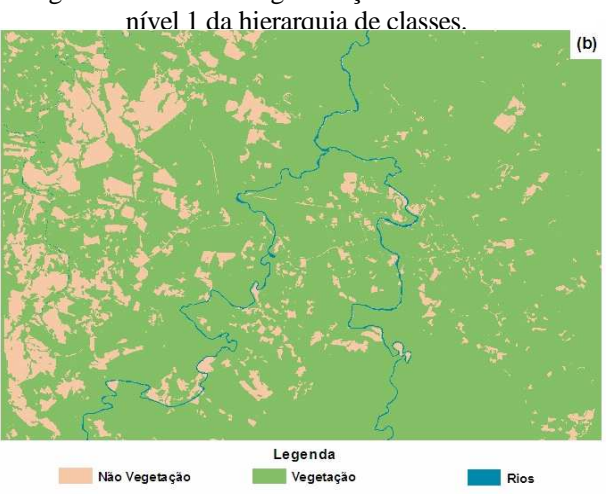

Imagem do nível 2 de segmentação classificada como nível 2 da hierarquia de classes.

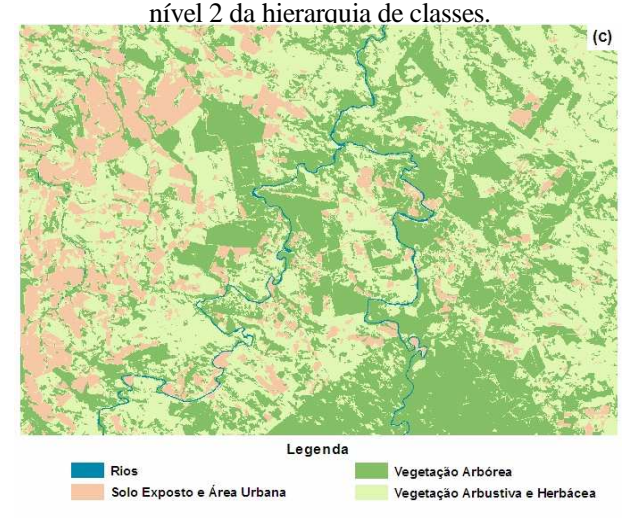

Imagem do nível 1 de segmentação classificada como nível 3 da hierarquia de classes.

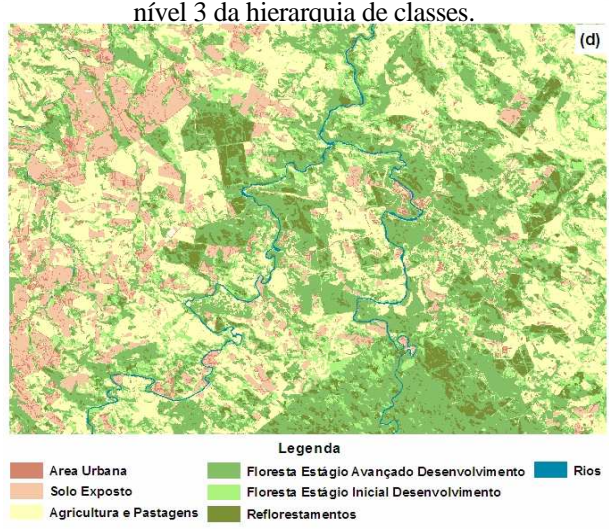

Figura 8. Resultados obtidos na classificação da imagem. Em (a), imagem original em composição com as bandas do vermelho, infravermelho e verde nos canais RGB, respectivamente. As letras (b), (c) e (d) indicam os resultados da classificação da imagem nos níveis 1, 2 e 3, resultantes das segmentações nos níveis 3, 2 e 1, respectivamente.

Figure 8. Results obtained with the image classification. In (a), original image in composition with the red, infra-red and green bands in RGB channels, respectively. The items (b), (c) and (d) denotes classification results on levels 1,2 and 3 from the segmentation levels 3,2 and 1 respectively.

No nível 2 de classificação, foram separadas 4 classes, havendo ainda pouca confusão entre as classes, fato corroborado pelos resultados apresentados na tabela 4 . Conforme se pode observar na referida tabela, a maior confusão ocorreu entre as classes de vegetação arbustiva e herbácea e vegetação arbórea. No entanto, ainda foram obtidos resultados considerados satisfatórios, já que os maiores erros de classificação não superaram $10 \%$ das amostras selecionadas, e a acurácia total obtida foi de 0,95 (de um valor máximo de 1). 
Tabela 3. Resultados da avaliação da acurácia da classificação realizada no nível 1 (objetos de imagem resultantes do nível 3 de segmentação).

Table 3. First level classification accuracy evaluation results (image objects from the third level of segmentation).

\begin{tabular}{lccc}
\hline Classes & Vegetação & Não-vegetação & $\boldsymbol{\Sigma}$ \\
\hline Vegetação & 967 & & 967 \\
Não-vegetação & & 366 & 366 \\
Não classificados & & 1 & 1 \\
\hline$\Sigma$ & 967 & 367 & 1334 \\
\hline
\end{tabular}

Tabela 4. Avaliação da acurácia da classificação realizada no nível 2 (objetos de imagem resultantes do nível 2 de segmentação).

Table 4. Second level classification accuracy assessment (image objects from the second level of segmentation).

\begin{tabular}{lcccc}
\hline Classes & $\begin{array}{c}\text { Veg. arbustiva e } \\
\text { herbácea }\end{array}$ & Vegetação arbórea & $\begin{array}{c}\text { Solo exposto e } \\
\text { área urbana }\end{array}$ & $\boldsymbol{\Sigma}$ \\
\hline Vegetação arbustiva e herbácea & 784 & 44 & & 828 \\
vegetação arbórea & 37 & 450 & 1 & 488 \\
Solo exposto e área urbana & 2 & & 394 & 396 \\
Não classificados & & 494 & 1 & 1 \\
\hline$\Sigma$ & 823 & & 396 & 1713 \\
\hline
\end{tabular}

Finalmente, na tabela 5, são apresentados os valores de confusão entre classes para a classificação da imagem resultante do nível 3 de segmentação. Para a classificação, 7 classes foram utilizadas, observando-se confusão entre as classes espectralmente mais próximas, quer sejam: reflorestamento e floresta em estágio avançado de desenvolvimento; floresta em estágio inicial de desenvolvimento e agricultura e pastagens; e finalmente área urbana e solo exposto. A classificação resultante apresenta maiores erros de classificação, no entanto superando os $10 \%$ de amostras erroneamente classificadas entre as classes de floresta em estágio avançado de desenvolvimento e reflorestamento, e floresta em estágio inicial de desenvolvimento e agricultura e pastagem. Apenas oito objetos não foram classificados, e a acurácia total ainda pode ser considerada satisfatória, resultando em 0,84 .

Tabela 5. Avaliação da acurácia da classificação realizada no nível 3.

Table 5. Third level accuracy assessment of the classification.

\begin{tabular}{|c|c|c|c|c|c|c|c|}
\hline Classes & 1 & 2 & 3 & 4 & 5 & 6 & $\Sigma$ \\
\hline 1. Agricultura e pastagens & 211 & 4 & & & 16 & & 231 \\
\hline 2. Área urbana & & 54 & 8 & & & & 62 \\
\hline 3. Solo exposto & & 9 & 82 & & & & 91 \\
\hline $\begin{array}{l}\text { 4. Floresta estágio avançado de } \\
\text { desenvolvimento }\end{array}$ & & & & 211 & 27 & 51 & 289 \\
\hline $\begin{array}{l}\text { 5. Floresta estágio inicial de } \\
\text { desenvolvimento }\end{array}$ & 14 & & & 1 & 87 & & 102 \\
\hline 6. Reflorestamento & & & & 22 & 1 & 206 & 229 \\
\hline Não classificados & 2 & 6 & & & & & 8 \\
\hline$\Sigma$ & 227 & 73 & 90 & 234 & 131 & 257 & 1012 \\
\hline
\end{tabular}

\section{CONCLUSÕES}

A avaliação preliminar da aplicação, não só do método de classificação orientada a objetos, mas também de segmentação multirresolução, apresentou resultados satisfatórios, pretendendo-se, portanto, prosseguir no desenvolvimento de uma metodologia para o mapeamento do uso do solo no estado do Paraná.

Quanto ao processo de segmentação da imagem, pode-se considerar bastante eficaz a análise visual dos polígonos resultantes na definição dos parâmetros de escala, já que os polígonos gerados devem estar de acordo com as feições de interesse e os objetivos do mapeamento. Segundo Pratt (2007), nenhum resultado 
de segmentação, mesmo que aprovado em testes quantitativos, será convincente se não satisfizer uma análise realizada pelos olhos humanos, que continua sendo a fonte mais robusta e experiente para a avaliação de técnicas de segmentação. Ainda segundo o autor, métricas quantitativas da avaliação dos resultados de segmentação ainda não são completamente estáveis e capazes de fornecer respostas precisas e indubitáveis. Apesar de ser uma questão ainda pendente, e da presença de bastante subjetividade, ainda, na definição dos valores dos parâmetros de segmentação (HAY; CASTILLA, 2006), considera-se desejável a inclusão de procedimentos quantitativos eficazes para avaliação dos resultados da segmentação na definição desses parâmetros. Essa tarefa deve consistir em objetivo a ser atingido em posteriores atividades de pesquisa, possivelmente avaliando a aplicabilidade de abordagens existentes (NEUBERT; MEINEL, 2003; NEUBERT et al., 2006; HEROLD et al., 2007; ZHANG, 1996).

A estrutura hierárquica e a rede semântica trazem muitos benefícios ao processo de classificação da imagem. A criação da rede semântica é um processo bastante intuitivo, fazendo sentido sob o ponto de vista das características das imagens e do comportamento espectral dos alvos e também quanto à interpretação da cena. A semelhança com uma chave de interpretação de imagens, como a que poderia ser elaborada analogicamente por um especialista humano, proporciona clareza ao processo de classificação, adicionando entendimento das relações entre as classes de uso da terra e as características das imagens.

A seleção de atributos consiste de uma etapa de suma importância em um processo de classificação de imagens como o abordado neste trabalho, já que o software utilizado permite o cálculo de um grande número de descritores dos objetos oriundos da segmentação. A abordagem utilizada, que envolve análises de componentes principais e de discriminantes, permitiu a redução de um conjunto de 360 atributos a um conjunto de apenas 39 atributos, aproximadamente $11 \%$ do número de descritores originais, sendo por esse aspecto considerada satisfatória. Adicionalmente, os resultados de classificação obtidos com os descritores selecionados corroboram a percepção de que essa abordagem pode ser adotada na redução da dimensionalidade dos dados. Essa abordagem, contudo, está voltada à seleção dos atributos mais representativos do conjunto original. Acredita-se que posteriores avanços devem ser atingidos na seleção dos atributos mais significativos ao processo de classificação da imagem, como, por exemplo, a indução de árvores de decisão e utilização dos atributos do topo da árvore na classificação da imagem.

Com relação aos resultados da classificação da imagem, de forma geral pode-se considerar que foram obtidos valores de acurácia total satisfatórios. Contudo, deve-se ressaltar a importância da obtenção de bons resultados em cada um dos níveis de classificação isoladamente, antes da continuidade do processo de classificação, já que os erros de determinado nível são herdados pelos objetos e classes-filha dentro da estrutura hierárquica e da rede semântica inerentes a essa abordagem. O primeiro nível de classificação da imagem, classificado em áreas cobertas com vegetação e áreas não cobertas com vegetação, resultou em um valor de acurácia total igual a 0,99 , satisfatório à continuidade do processo de classificação. A acurácia total do segundo nível de classificação resultou em 0,95 , sendo que foram classificados como solo exposto e áreas urbanas os polígonos anteriormente incluídos na classe de áreas não cobertas por vegetação. Somente a classe de áreas cobertas com vegetação, na classificação do primeiro nível, foi subdividida e classificada em duas classes: a de vegetação arbustiva e herbácea e a de vegetação arbórea. A confusão observada entre essas duas classes foi de $5 \%$ a $8 \%$. Além de esses erros terem sido herdados pelos objetos do terceiro nível de classificação, podem ter contribuído com a confusão entre floresta em estágio avançado de desenvolvimento e floresta em estágio inicial de desenvolvimento, cujos erros variaram de 9 a $13 \%$. No entanto, os resultados são considerados promissores, tanto em termos de acurácia entre as classes como em termos de acurácia total, que resultou em 0,84 para o mapeamento final do uso do solo.

Finalmente, de acordo com a qualidade dos resultados obtidos, pretende-se comparar essa técnica de classificação com a pixel a pixel atualmente adotada pelo projeto que desenvolve o mapeamento do uso do solo do estado do Paraná, bem como classificações-padrão realizadas através da interpretação visual da imagem.

\section{REFERÊNCIAS}

ANTUNES, A. F. B. Classificação de ambiente ciliar baseada em orientação a objeto em imagens de alta resolução espacial. 2003. 147 f. Tese (Doutorado em Ciências Geodésicas) - Universidade Federal do Paraná, UFPR, Curitiba, 2003.

ARGIALAS, D.; TZOTSOS, A. Automatic extraction of physiographic features and alluvial Fans in Nevada, USA from digital elevation models and satellite imagery through multiresolution segmentation 
and object-oriented classification. In: Proceedings of the American Society for Photogrammetry and Remote Sensing (ASPRS) Annual Conference, 2006, Reno, Nevada. Proceedings... p. 150.

AVCI, D. U.; GÖRAL, B.; AKKARTAL, A.; SUNAR, F. Flood monitoring using multi-temporal radarsat-1 images. In Proceedings of the Remote Sensing and Photogrammetry Society (RSPSoc) Annual Conference, 2006, Newcastle, UK. Proceedings... p. 12-14.

BAATZ, M.; SCHÄPE, A. Multiresolution Segmentation - an optimization approach for high quality multi-scale image segmentation. In: STROBL, J. et al. (Hrsg.): Angewandte Geographische Informationsverarbeitung XII. Beiträge zum AGIT-Symposium Salzburg, Karlsruhe, Herbert Wichmann Verlag: 12-23. 2000. 2000. Disponível em www.definiens.com. Acesso em julho 2007.

Object-Oriented and Multi-Scale Image Analysis in Semantic Networks. In: Procedings... of the 2nd Int. Symposium on Operationalization of Remote Sensing, Enschede, Netherlands, 1999.

BARROS, L. C. Sobre conjuntos fuzzy. Revista do Professor de Matemática, São Paulo, v. 56, p. 2-9, 2005.

BLASCHKE, T.; STROBL, J. What's wrong with pixels? Some recent developments interfacing remote sensing and GIS. In: GeoBIT/GIS 6: 12-17. 2001. Disponível em: 〈http://www.definiens.com>. Acesso em julho de 2007.

CHUBEY, M. S.; FRANKLIN, S. E.; WULDER, M. A. Object-based analysis of Ikonos-2 imagery for extraction of forest inventory parameters. Photogrammetric Engineering \& Remote Sensing, v. 72, n. 4, p. 383-394, 2006.

CHUNYANG, H.; LI, J.; ZHANG, J.; PAN, Y.; CHEN, Y. H. Dynamic monitor on urban expansion based on a object-oriented approach. In: Proceedings of the International Geoscience and Remote Sensing Symposium (IGARSS'2005), Julho 2005, Seoul, Korea. Proceedings... p. 25-29.

DEFINIENS IMAGING. User Guide 4.0. eCognition, 468p. 2004. Disponível em http://www.pcigeo matics.com/ products/definiens.html. Acessado em julho de 2007.

EHLERS, M.; MICHEL, U.; BOHMANN, G.; TOMOWSKI, D. Decision based data fusion techniques for the analysis of settlement areas from multisensor satellite data. In: Proceedings of the American Society for Photogrammetry and Remote Sensing (ASPRS) 2006 Annual Conference, May 2006, Reno, Nevada. Proceedings... p. 150.

FRAUMAN, E.; WOLFF, E. Segmentation of very high spatial resolution satellite images in urban areas for segments-based classification. In: International Society for Photogrammetry and Remote Sensing (ISPRS) 3rd International Symposium Remote Sensing and Data Fusion Over Urban Areas (URBAN 2005) and 5th International Symposium Remote Sensing of Urban Areas (URS 2005), March Tempe, AZ, USA. Proceedings... p. 14-16.

GONZALES, R.; WOODS, R. Processamento de imagens digitais. São Paulo: Ed. Edgard Blüchner, 2000. 509 p.

HAY, G. J.; CASTILLA, G. Object-based image analysis: strengths, weaknesses, opportunities and threats (SWOT). In: Lang, S.; BLASCHKE. T.; Schöpfer, E. (eds.). Proceedings of the 1st INTERNATIONAL CONFERENCE ON OBJECT-BASED IMAGE ANALYSIS, 1., 2006, Salzburg. Proceedings... Salzburg: International Society for Photogrammetry and Remote Sensing - ISPRS, 2006. Disponível em: <http://www.commission4.isprs.org/obia06/papers.htm > Acesso em 29/06/2008.

HEROLD, H.; NEUBERT, M.; MEINEL, G. Avaliação quantitativa da segmentação de imagens de sensoriamento remoto: conceitos e mais resultados. In: XIII SIMPÓSIO BRASILEIRO DE SENSORIAMENTO REMOTO, 13. 2007, Florianópolis. Anais... São José dos Campos: Instituto Nacional de Pesquisas Espaciais - INPE, p. 5823-5825, 2007.

KERSTING, A. P. B. Mapeamento de obstáculos sob a faixa de domínio de linhas de transmissão usando uma abordagem orientada a objeto, tecnologia LIDAR e câmara digital de pequeno formato. 173 f. Dissertação (Mestrado em Ciências Geodésicas), Universidade Federal do Paraná, UFPR, 2006. 
MACHADO, F.; CAETANO, M. Detecção de alterações de ocupação do solo com uma abordagem orientada por objectos. In: International Symposium on Remote Sensing of Environment, 9, 2002, Buenos Aires, Argentina. Proceedings...

MOELLER, M. S.; BLASCHKE, T. A new index for the differentiation of vegetation fractions in urban neighbourhoods based on satellite imagery. In: Proceedings of the American Society for Photogrammetry and Remote Sensing (ASPRS) Annual Conference, 2006, Reno, Nevada. Proceedings... p. 150.

MOLENAAR, M.; CHENG, T. Fuzzy spatial objects and their dynamics. ISPRS Journal of Photogrammetry \& Remote Sensing, v. 55, p.164-175, 2000.

NEUBERT, M.; HEROLD, H.; MEINEL, G. Evaluation of remote sensing image segmentation quality further results and concepts. International Archives of Photogrammetry, Remote Sensing and Spatial Information Sciences, v. XXXVI, n.4/C42, Salzburg, Austria, 2006.

NEUBERT, M.; MEINEL, G. Evaluation of segmentation programs for high resolution remote sensing applications. In: SCHROEDER, M.; JACOBSEN, K.; HEIPKE, C. (eds.): PROCEEDINGS OF THE JOINT ISPRS/EARSEL WORKSHOP: HIGH RESOLUTION MAPPING FROM SPACE, 2003, Hannover. Proceedings... Hannover: International Society for Photogrammetry and Remote Sensing ISPRS, 2003. 1 CD-Room.

PINHO, C. M. D.; FEITOSA, F. F.; KUX, H. Classificação automática de cobertura do solo urbano em imagens IKONOS: comparação entre a abordagem pixel a pixel e orientada a objetos. In: Simpósio Brasileiro de Sensoriamento Remoto, 12, 2005, Goiânia. Resumos... São José dos Campos, SP, Instituto Nacional de Pesquisas Espaciais (INPE), 2005. p. 4568.

PRATT, W. Digital image processing: PIKS scientific inside. 4. ed. New York: J. Wiley, 786 p., 2007.

RUHOFF, A. L.; SOUZA, B. S. P.; GIOTTO, E.; PEREIRA, R. S. Lógica Fuzzy e zoneamento ambiental da Bacia do Arroio Grande. In: Simp. Bras. de Sensoriamento Remoto, 12, 2005, Goiânia. Resumos... São José dos Campos, SP: Instituto Nacional de Pesquisas Espaciais (INPE), 2005. p. 4568 p. 2355-2362.

SABINS, F. F. Remote sensing: principles and interpretation. New York: W. H. Freeman and Company, 1987. 449 p.

SHIBA, M.; ITAYA, A. Using eCognition for improved forest management and monitoring systems in precision forestry. In: International Precision Forestry Symposium, March 2006, Stellenbosch, South Africa. Proceedings... p. 351-359.

TAVARES JR., J. B.; OUVERMEY, M. L. M.; UBERTI, M. S.; ANTUNES, M. A. H. Avaliação de Imagens Ikonos II e Quickbird para Obtenção de Bases Cartográficas para o Cadastro Técnico Municipal. In: Cong. Bras. de Cadastro Técnico Multifinalitário e Gestão Territorial, 7, 2006, Florianópolis. Resumos...

WHITESIDE, T.; AHMAD, W. A comparison of object-oriented and pixel based classification methods for mapping land cover in North Australia. In Spatial Science Institute Biennial Conference SSC2005. Spatial Intelligence, Innovation and praxis, 2005, Melbourne, Australia. Proceedings...

WILLHAUCK, G.; SCHNEIDER, T.; DE KOK, R.; AMMER, U. Comparison of object oriented classification techniques and standard image analysis for the use of change detection between SPOT multispectral satellite images and aerial photos. In: Congress of the International Society for Photogrammetry and Remote Sensing, 19, 2000, Amsterdam, Holanda. Proceedings... CD-room.

ZHANG, Y.; MAXWELL. T. A fuzzy logic approach to supervised segmentation for object-oriented classification. In: Proceedings... of ASPRS 2006 Annual Conference, Reno, Nevada; May 1-5, 2006.

ZHANG, Y. J. A survey on evaluation methods for image segmentation. Pattern Recognition, v. 29, n. 8, p. 1335-1346, 1996.

ZHONG, C.; ZHONGMIN, Z.; DONGMEI, Y.; RENXI, C. Multi-scale segmentation of the high resolution remote sensing image, 2005. Disponível em: <http://ieeexplore.ieee.org/iel5/10226/32 599/01526648.pdf? arnumber=1526648>. Acesso em 02 jul. 2007. 
FLORESTA, Curitiba, PR, v. 40, n. 2, p. 429-446, abr./jun. 2010.

Luz, N. B. da; Antunes, A. F. B.; Tavares Júnior, J. B. 